\title{
El cuerpo negociado, el cuerpo mercancía. Trabajo sexual y precarización de la vida en Ciudad Juárez, México
}

\section{The negotiated body, the body as merchandise. Sex work and life precariousness in Ciudad Juarez, Mexico}

\author{
doi: https://doi.org/ \\ 10.32870/eees.v26i75.6963
}

\section{Resumen}

Este artículo pretende mostrar resultados de un estudio enfocado en las experiencias de vida de jóvenes trabajadoras sexuales del centro histórico de Ciudad Juárez (México). A partir del análisis de entrevistas a profundidad, se pone atención en la construcción de la experiencia subjetiva del sentido de la vida de mujeres jóvenes provenientes de estratos socioeconómicos bajos y que han tenido que vincularse al mundo paralegal del trabajo sexual con la intención de mitigar el escenario de pobreza que enfrentan. El aporte de la investigación radica en que se separa de visiones normativas-punitivas que han dominado el debate en torno al fenómeno, para abordar la construcción de la experiencia de vida de las jóvenes, quienes generan tácticas de negociación ante la creciente precarización que caracteriza su entorno cotidiano.

Palabras clave: trabajo sexual, precarización, violencia sistémica, experiencia subjetiva, Ciudad Juárez.

\author{
Salvador Salazar Gutiérrez \\ Martha Mónica Curiel García••
}

\begin{abstract}
This article looks for showing results of an study about life experiences in young sex workers in the historic center of Ciudad Juarez (Mexico). Based on the qualitative interview analysis, the document focuses on the construction of the subjective experience of the meaning of life of young women from low socio-economic strata, who have had to link to the paralegal world of sex work with the intention of mitigating the scenario of poverty that they face. Its originality lies in separating normative-punitive visions that have dominated the debate around sex work, to address the construction of the life experience of young women -who generate negotiation tactics for the growing precarization that characterizes their daily environment.
\end{abstract}

Keywords: Sexual work, precarious life, systemic violence, subjective experience, Ciudad Juarez.

- Profesor-Investigador del Cuerpo Académico de Estudios de Ciudad de la Universidad Autónoma de Ciudad Juárez (UAC)), México. ORCID: http://orcid.org/0000-0002-5205-4743 salvador.salazar@uacj.mx

- Profesora-Investigadora del Cuerpo Académico de Estudios de Ciudad de la Universidad Autónoma de Ciudad Juárez (UAC)), México. ORCID: http://orcid.org/0000-0003-I I I5-0955 martha.curiel@uacj.mx

Fecha de recepción: 26 de junio de 2018. Fecha de aceptación: 23 de enero de 2019. 


\section{Introducción}

En México, el trabajo sexual ha sido uno de los fenómenos con presencia constante en la vida en la frontera, con una histórica vinculación a un imaginario dominante que lo ha caracterizado como una manifestación de inmoralidad.

Así, por ejemplo, no se puede entender el estigma asociado a una leyenda negra que ha caracterizado a Ciudad Juárez, urbe fronteriza de México, en diversos periodos de su historia, sin tener presente la dinámica del mercado sexual vinculado al giro de la diversión indecente (García Pereyra, 2013) que caracterizó a la frontera desde la época posrevolucionaria (Valenzuela Arce, 2012). ${ }^{1}$

Esta dinámica del mercado del trabajo sexual ${ }^{2}$ en Ciudad Juárez conlleva la experiencia de vida de mujeres jóvenes que han encontrado en dicho mercado no sólo un escenario de precarización anclado a una cultura misógina que las ha reducido a objetos de deseo, sino una opción para la generación de tácticas de negociación por servicios a las que en otros espacios laborales simplemente no podrían acceder, lo que genera a su vez bienes materiales indispensables para ellas y sus redes de vinculación directa (mundo familiar). Como plantean Santiago Morcillo y Cecilia Varela, "la denominación trabajadora sexual aparece como una de las formas de luchar contra la estigmatización y, al mismo

I. Existe literatura interesante en relación a la leyenda negra de Ciudad Juárez a partir de los años veinte del siglo pasado. Valenzuela Arce (20I2) menciona que no se puede comprender la violencia sistémica que ha enfrentado esta ciudad fronteriza en los últimos años, y en particular el fenómeno del feminicidio, sin remitirse a las implicaciones de lo que fue la llamada LeyVolstead-acta de prohibición estadounidense, o Ley Seca-, de 1919, que generó un crecimiento de la vida nocturna y actividades no legales vinculadas a ella tras el prohibicionismo impuesto en los Estados Unidos.

2. Cobra relevancia la distinción entre los términos prostitución y trabajo sexual. El primero carga con una connotación histórica moralista y de una ideología sexista que estigmatiza a la mujer como un objeto de deseo. Hablar de trabajo sexual, en cambio, presupone la existencia de una relación clientelar en la que se asume un acuerdo entre dos o más personas. Al respecto, Melissa Gira aclara que "tanto 
tiempo, tender puentes entre mujeres [que trabajan] en distintos sectores del mercado sexual (prostitutas, actrices porno o bailarinas eróticas)" (Morcillo y Varela, 2016, p. 10).

No es la intención de este trabajo analizar con corte normativo-punitivo los derechos de las trabajadoras sexuales, así como las implicaciones económicas y sociales que este tipo de mercado plantea en el escenario de la frontera. Más bien, como hipótesis central, se sostiene que la inserción de jóvenes mujeres en el trabajo sexual en Ciudad Juárez, si bien les permite a ellas, como ya se dijo, acceder a un pago que en otros espacios laborales formales les sería negado a causa de la exclusión y negación de las que son objeto, es una actividad que incrementa la precarización de sus trayectorias de vida al estar sometida a un imaginario androcéntrico que ve en los cuerpos femeninos un recurso de sometimiento y control.

Como se podrá observar a lo largo del artículo, se analiza la categoría trabajo sexual y no tanto prostitución, ya que este término carga con una connotación que estigmatiza a la mujer en un contexto dominante heteronormativo. ${ }^{3}$ En México, se ha generado una serie de estudios en torno al mercado sexual más allá de una visión normativa-punitiva (Lamas, 2014), y en los últimos años, el estudio del fenómeno en contextos de violencia ha cobrado relevancia desde una mirada sociocultural (Segato, 2006). Considerando esta observación, interesa centrar la atención en la experiencia

la prostitución como el trabajo sexual son construcciones sociales y, por tanto, históricamente específicas" (Gira Grant, 2016, p. II).

3. Judith Butler, en su texto Cuerpos que importan, aclara lo siguiente: "el sexo no sólo funciona como norma: es parte de una práctica reguladora que produce los cuerpos que gobierna, cuya fuerza reguladora se manifiesta como una especie de poder productivo, el poder de producir los cuerpos que controla" (Butler, 20I0, p. 18). Al respecto, la categoría prostitución, como ya se dijo, está anclada en un contexto sociohistórico de dominación neoliberal en la que cada vez se somete con mayor voracidad la relación cuerpo femenino-mercancía. 
subjetiva de mujeres jóvenes ${ }^{4}$ provenientes de estratos socioeconómicos bajos que son obligadas a insertarse al mundo paralegal ${ }^{5}$ del trabajo sexual.

En relación a la metodología, para el estudio se realizaron diez entrevistas a profundidad con mujeres jóvenes (entre los dieciséis y los veinticinco años de edad), trabajadoras sexuales en la zona del centro histórico de Ciudad Juárez. ${ }^{6}$ La entrevista a profundidad permite "encuentros repetidos cara a cara entre investigador e informante, los cuales se orientan a entender las perspectivas del entrevistado sobre su vida, experiencia o situaciones personales tal y como son expresadas en sus propias palabras" (Taylor y Bogdan, 1996, p. 48).

A partir de un trabajo de observación en campo, durante cuatro meses se visitó la zona centro de la ciudad, caracterizada por la presencia de centros nocturnos, bares y fincas viejas que sirven de hoteles improvisados que favorecen el trabajo sexual. Las preguntas de las entrevistas estuvieron integradas en cuatro ejes de análisis: antecedentes biográficos de las entrevistadas, motivos de incorporación al trabajo sexual, mecanismos o vínculos de redes que favorecen o condicionan sus prácticas como trabajadoras sexuales, y

\footnotetext{
4. El presente trabajo forma parte de un proyecto de investigación financiado por el fondo Ciencia Básica del Consejo Nacional de Ciencia y Tecnología (Conacyt), titulado Del régimen estético de la exclusión-negación, a las trayectorias sensibles de la memoria: experiencia biográfica juvenil en el mercado sexual en Ciudad Juárez, México. Su objetivo central es analizar cómo se construye la experiencia de vida en jóvenes dedicados al mercado sexual en Ciudad Juárez, en un contexto dominado por procesos de exclusión, precarización y violencia.

5. Rossana Reguillo (2010) plantea a partir de esta categoría una zona fronteriza entre el binomio legalidad-ilegalidad," que emerge justo en la zona fronteriza abierta por las violencias, generando no un orden ilegal, sino un orden paralelo que genera sus propios códigos, normas y rituales $[y]$ que al ignorar olímpicamente a las instituciones y al contrato social se constituye paradójicamente en un desafío mayor que la ilegalidad" (p. 34).

6. Las entrevistas a profundidad se realizaron en contacto directo y continuo con varias de las jóvenes trabajadoras sexuales de la zona. Se llevaron a cabo a media mañana, con apoyo de grabadora digital y en compañía con una compañera investigadora que favoreció la confianza con las entrevistadas.
} 
miedos o expectativas asociadas a la actividad. ${ }^{7}$ Las respuestas permitieron abordar la pregunta de investigación: ¿cómo se construye la experiencia de vida precaria desde la mirada de jóvenes mujeres insertas en el mercado sexual, en el contexto reciente de la ciudad fronteriza de Ciudad Juárez, México?

El artículo se divide en tres apartados. El primero plantea un breve recorrido en torno a los debates contemporáneos con respecto a la visión normativo-punitiva del trabajo sexual. El segundo muestra el resultado del análisis de las entrevistas realizadas, considerando los cuatro ejes antes mencionados. Finalmente, un tercer apartado constituye una ruta de interpretación que relaciona la experiencia de las jóvenes y la producción de vidas precarias en contextos crecientes de violencia y exclusión social.

Si bien las jóvenes manifestaron una libre elección para dedicarse a esta actividad, la experiencia en campo, tanto en las entrevistas como en la observación, permitió dar cuenta del peso de una masculinidad hegemónica y sus mecanismos de control sobre los cuerpos de las jóvenes.

\section{El debate normativo-moral del trabajo sexual}

Si bien el presente trabajo centra su atención en la experiencia de las jóvenes trabajadoras sexuales, es relevante repasar cómo ha sido abordado el entendimiento del cuerpo y la sexualidad en relación al trabajo sexual desde diversas perspectivas. Se identifican en concreto las de tipo prohibi-

7. El grupo de trabajo, integrado por una investigadora, una asistente en campo y un investigador, acordó con cada joven entrevistada el acceso a sus respectivos espacios de trabajo para llevar a cabo las entrevistas y acompañarla a sus hogares. En todo momento, se privilegió una relación de confianza, confidencialidad y valoración-reconocimiento a la práctica del trabajo sexual que ellas ejercen, así como se dotó de claridad a las entrevistadas respecto de las intenciones de la investigación y sobre cómo serían utilizados los datos recopilados en la experiencia en campo. 
cionista, abolicionista, reglamentarista y laboralista (Villa Camarma, 2010). Cada una de ellas tiene como eje común el significado que otorga al discurso del cuerpo femenino, y en especial al del trabajo sexual.

Las cuatro perspectivas en torno al cuerpo y la sexualidad que recupera Villa Camarma (2010) son el cuerpo como delito, el cuerpo como negocio, el cuerpo como mercancía y el cuerpo como poder.

\section{I.I. El cuerpo como delito}

Esta perspectiva ha dominado el imaginario normativo en relación al trabajo sexual. Parte de considerar al mercado de servicios sexuales como un atentado a valores éticos: la gestión sexual del cuerpo femenino resulta ser oficialmente un delito de carácter moral y legal, que provocaría la perdición y corrupción de los valores tradicionales (Villa Camarma, 2010, p. 159).

En esta perspectiva, el Estado se coloca como una instancia de control del orden y un guardián de la moral compartida, por lo que se asume que la generación de un andamiaje prohibicionista y persecutorio es el marco adecuado de actuación frente al trabajo sexual. La institucionalidad punitiva insertada en la estructura policial del Estado (instituciones de seguridad pública o salubridad, policías, centros de reinserción social) es la encargada de proveer los marcos normativos y operativos que salvaguardan el orden moral que castiga la mercantilización de los cuerpos femeninos con fines sexuales. Como resultado de ello, quien ejerce el trabajo sexual carga con un estigma de amenaza que incrementa su indefensión social y vulnerabilidad.

Aquí se ubican, en gran medida, perspectivas abolicionistas que han tenido una presencia importante en la regulación y control de esta actividad. En el caso específico de México, las medidas punitivas a partir de la llamada Ley para prevenir, erradicar y sancionar los delitos en materia 
de trata de personas y para la protección y asistencia de las víctimas, publicada el 14 de junio de 2012, asocian el mercado sexual a una condición de explotación de víctimas a partir de la categoría del lenocinio.

Martha Lamas (2014) plantea que detrás de este tipo de recursos legales lo que está es más bien una perspectiva estigmatizante y moralista del trabajo sexual, que reduce a una condición de víctimas a las trabajadoras sexuales y deja fuera la reflexión sobre factores estructurales - pobreza, precariedad de empleos, violencias, etc.- que están detrás de la decisión de las mujeres de cobrar por sus servicios sexuales: "el discurso de salvar víctimas ha ampliado la estrategia policial del rescate[;] el abolicionismo intenta fijar un límite en qué se debe considerar lo decente y moralmente aceptado en torno a la conducta sexual" (Lamas, 2014, p. 37).

\section{I.2. El cuerpo como negocio}

En un sentido distinto, aunque no desvinculado del punto anterior, perspectivas reglamentaristas y laboristas plantean la regulación comercial de los negocios sexuales. Reglamentar esta práctica significa generar un recurso de excepcionalidad en el derecho penal para aquellos sujetos que se dedican al mercado sexual. A partir de mecanismos de control policial y sanitario, se genera la estrategia de legalizar el trabajo sexual, siempre y cuando este se desarrolle en espacios controlados y cooptados por el orden institucional.

El discurso laborista se encarga de sostener a la prostitución como cualquier trabajo, en el sentido de defender su reconocimiento en los marcos de la regulación laboral formal. Si bien esto parecería a su vez reconocer a quienes realizan esta práctica, no significa que bajo esta perspectiva no aparezcan condiciones de explotación y mercadeo del cuerpo por parte de terceros: "la defensa regular de los derechos y la mejora de las condiciones laborales en el mercado del sexo se debe[n] apoyar en la reivindicación de 
la libertad de decisión sobre la gestión del propio cuerpo, como negocio autónomo" (Villa Camarma, 2010, p. 163).

En este sentido, si bien en México no se encuentra tipificada la prostitución como delito del fuero común, sino como falta administrativa que implica la alteración del orden, el Código Penal Federal, en su artículo 204, establece como delitos federales merecedores de una pena de ocho a quince años de prisión aquellos que induzcan al mercado sexual a menores de dieciocho años de edad o a personas que no tienen la capacidad para comprender el significado del hecho. ${ }^{8}$

\section{I.3. El cuerpo como mercancía}

A diferencia de las perspectivas señaladas hasta aquí, en la del cuerpo como mercancía el trabajo sexual está asociado a una forma de esclavitud en la que ser prostituta es ser víctima de una trayectoria de sumisión y sometimiento dentro de un espacio cotidiano que tiene como prevalecientes condicionantes estructurales de la experiencia de vida de las prostitutas, como la pobreza, la marginalidad, el abuso sexual, la falta de oportunidades laborales y educativas o la presencia del narcotráfico.

Aquí, en oposición a marcos normativos que permiten dar visibilidad a derechos y reconocimiento a esta actividad, el trabajo sexual está vinculado a una condición forzada de esclavitud sexual.

\section{I.4. El cuerpo como poder}

Este cuarto eje lo constituyen aquellas posturas de corte feminista, que sostienen la reivindicación de la libre elección de la mujer en la gestión de su cuerpo (Gimeno, 2011). Históricamente en México, la figura de la prostituta ha referido a la imagen de mala mujer, en contraposición a la de mujer virtuosa, que se atribuye a la esposa fiel y ama 
de casa. ${ }^{9}$ En este sentido, Raquel Osborne (1989) sostiene que si bien el trabajo sexual está vinculado a la desigualdad social estructural entre hombres y mujeres, esto no significa que reconocerlo haga a un lado las reivindicaciones de los derechos de estas mujeres.

Frente al abolicionismo, que niega la libre voluntad de las mujeres trabajadoras sexuales y las ubica como receptoras de violencia, la visión del cuerpo como poder plantea una agencia de alcance significativo para la conquista de su reconocimiento y autonomía. Aquí, algunas autoras (Juliano, 2002; Petherson, 2002) llaman la atención sobre que la estigmatización de quien ejerce el trabajo sexual, por ejemplo, mediante la utilización del término puta, no es resultado exclusivo de su actividad, sino forma parte de una construcción sociocultural que obedece a procesos de racionalidad de una dominación de género, en la cual ser mujer es asumir una obligación de sumisión frente al dominio masculino.

En síntesis, esta perspectiva y sus autoras desenmascaran modelos sociales construidos que a su vez se encargan de moldear conductas sociales en las cuales ser mujer buena, sumisa, obediente y que satisface es la figura valorada: "La atención no se debe ubicar en torno a la práctica de la prostitución en sí, sino en las reivindicaciones de las mujeres que la ejercen y el análisis de las construcciones sociales relacionadas con el sexo femenino como forma de control social” (Villa Camarma, 2010, p. 176).

Estas cuatro trayectorias permiten observar cómo se han producido rutas de interpretación e implementación de estrategias -represivas, de control, de sanción- en diversos periodos históricos en México. En el caso específico de la ciudad fronteriza bajo estudio, prevalece una creciente

9. Al respecto, se recomienda el libro Vicio, prostitución y delito. Mujeres transgresoras en los siglos XIX y XX, de Speckman Guerra y Bailón Vásquez (20I6). 
estigmatización de las mujeres jóvenes frente al marco normativo y axiológico que los espacios sociales tradicionales han producido en relación al cuerpo y la sexualidad. Ser mujer, joven, pobre, prostituta es enfrentar una permanente vulnerabilidad en la que ofrecer servicios sexuales no constituye una decisión enmarcada en protección de derechos o una libre elección, sino forma parte de un escenario de precarización en el que el cuerpo de la joven está asociado a una mercancía de satisfacción, con una intención negociadora para acceder a un pago por tiempo de trabajo pactado.

Si bien cobra relevancia describir este marco interpretativo en torno a cómo ha sido problematizada la temática del mercado sexual y la prostitución, en el siguiente apartado se aborda desde la experiencia subjetiva, plasmada en las entrevistas a profundidad realizadas, cómo se genera una experiencia de vida precaria en el trabajo sexual.

Según datos del Centro Ambulatorio para la Prevención y Atención en Sida e Infecciones de Transmisión Sexual (CAPASITS $)^{10}$ delegación Ciudad Juárez, en agosto del 2016 existían 4600 mujeres que ejercían el trabajo sexual en diversas zonas de la ciudad bajo estudio. Del total de esta población, el mayor porcentaje estaba formado por mujeres jóvenes menores de treinta años.

La zona centro de la ciudad destacaba como el lugar donde se ubicaba gran parte de ellas. El llamado centro histórico de Ciudad Juárez ha sido el escenario en el que se ha encarnado con mayor presencia la ya mencionada leyenda negra de esta ciudad fronteriza, y es ahí donde se ubica un número importante de experiencias de vida de jóvenes que, al ser desplazadas de las trayectorias dominantes que definen los recorridos legítimos y hegemónicos de ser jóvenes, se ven

10. El CAPASITS es una unidad de salud ambulatoria que proporciona servicios para la prevención y atención especializada de pacientes que viven con virus de inmunodeficiencia humana $(\mathrm{VIH})$ y enfermedades de transmisión sexual. Este tipo de unidades brinda el servicio de prevención y promoción como parte fundamental

\section{8}


obligadas a insertarse en el mundo clandestino del mercado sexual como única opción de vida.

\section{Biografías y experiencias en el mundo del trabajo sexual}

\section{I.Trayectoria biográfica del trabajo sexual}

La observación realizada en la intersección de las calles Mariscal y La Paz, en el centro histórico de Ciudad Juárez, permite detectar un espacio urbano caracterizado por una dinámica de importante movimiento de habitantes, que se dirigen desde temprana hora a diversos negocios: farmacias, tiendas de empeño, establecimientos de comida -llamados fondas-, ventas de abarrotes, así como tendederos de artículos usados -o segundas- improvisados en alguna pared o reja metálica de alguna escuela o centro de salud.

También, se detectan vehículos, en su mayoría con placas de frontera, que se desplazan lentamente entre el movimiento de peatones, que transitan en las banquetas ocupadas por la mercancía que ofrecen las tiendas y puestos de tianguis (comercio de paso) en los que se ofertan alimentos preparados, verduras, frutas, hierbas medicinales, discos de música o películas piratas, propias del mercado informal. ${ }^{11}$

El espacio de observación se caracteriza entonces como un paisaje marcado por la tensión legallilegal en el que ha tenido una presencia importante el mundo del trabajo sexual. También, aprovechándose de una infraestructura urbana frágil, con una institucionalidad oficial históricamente endeble, los vínculos generados en torno al trasiego de droga y su mercado han favorecido ese escenario en el

de sus funciones, además de que otorga apoyo psicológico y de trabajo social tanto a las personas afectadas como a sus familiares. Entre estos servicios, brinda acceso al tratamiento antirretroviral para todas las personas con VIH que no están cubiertas por regímenes de seguridad social.

II. El centro histórico de la ciudad se ha caracterizado por la existencia de mercadeo informal de productos de segunda mano, a bajo costo. 
que la oferta del mercado sexual ha adquirido presencia importante.

En el espacio de observación, entre edificios deteriorados, se ingresa por una pequeña puerta a un inmueble con una serie de habitaciones. En ellas, se constata la presencia de cinco a siete mujeres de diversas edades, de pie o sentadas en algunas sillas, con vestidos cortos entallados, que se encuentran a la espera de clientes con quienes negociar sus servicios.

Esta escenificación descrita es característica de

culturas patriarcales [que] definen a los hombres como más importantes que las mujeres, $y$ enseñan visiones estereotipadas acerca de para qué sirven y cómo deberían comportarse las mujeres. Es un panorama hegemónico en el cual la masculinidad enfatiza el poder y la dominación, $y$ un sentido entre hombres de un derecho a ejercer su poder sin restricción. (Connel, 2003, p. 262)

Dicho esto, la observación realizada en campo permite afirmar que el centro de Ciudad Juárez se ha constituido en espacio de un mercado que se mueve en la dinámica de oferta y demanda, sobre todo con el protagonismo de una población masculina que, inserta en la dinámica cultural de dominación heteropatriarcal ${ }^{12}$ característica de la vida en la frontera, ve en las jóvenes sexoservidoras un mal necesario.

Con la finalidad de entretejer el análisis a partir de experiencias de vida específicas recopiladas, en los siguientes párrafos se reproducen fragmentos de historias de vida de mujeres jóvenes, que tienen como común denominador la ostentación de una posición de exclusión que las obliga a acceder a ese mercado de dominación masculina que, como se dijo, las reduce a objetos de placer:

12.Aquello que Butler refiere como "el fantasma normativo de una heterosexualidad obligatoria que opera a través de la naturalización de normas heterosexistas" (Butler, 2010, p. 144). 
Yo inicié ya hace tres años. Fui la primera vez [...] con una amiga que me dijo que podía sacar dinero. Fue difícil, me sentí bastante sucia, sobre todo porque era la primera vez y no sabía qué hacer. Las otras compañeras tratan de guiarte, pero cuando estás ahí tienes que ser muy cabrona porque si no abusan de [ti], sobre todo los que llegan tomados, [que] quieren más de lo que se acordó, y si se pasan gritamos para que nos ayuden las otras. (Joven I, 2016) ${ }^{13}$

A mí me invitó mi hermana. Ella trabajó aquí pero ya no está, pudo pasar al otro lado [Estados Unidos] y no sabemos de ella.Tengo poco tiempo [ejerciendo el trabajo sexual], tres meses. Me sigue dando mucho miedo, tengo diecisiete años, y sí te paniqueas [atemorizas] cuando ves al que entra al cuarto. Pero no tengo opción, no estudié, no tengo nada más. Vivo con mi abuelita y con mis tres sobrinitas, $y$ tengo que ayudarla. Nadie se hace cargo de nosotras. Aquí puedo sacar hasta quinientos pesos diarios por tres o cuatro horas [de trabajo]. En la maquila ${ }^{14}$ tendría que trabajar toda la semana para [ganar] eso. (Joven 2, 2016)

Los relatos constituyen rutas de interpretación comunes en torno a la condición de precariedad que enfrentan estas mujeres jóvenes. Como se puede observar, su participación en el mercado del trabajo sexual es resultado de sus vínculos directos tanto con el mundo familiar como con alguna pareja: la hermana, prima o amiga que motiva a la joven a probar tener sexo con alguien que no conoce a cambio de un pago al que en otro escenario laboral simplemente no podría acceder; el hombre con el que las entrevistadas iniciaron una relación y que exige que se prostituyan por un pago que a su vez será retribuido con el vínculo afectivo.

Todas las jóvenes entrevistadas tenían en común haber sido madres a una edad temprana. A partir de los trece o

I3. En lo sucesivo, se señala el seudónimo de la entrevistada al final del fragmento en cuestión. El seudónimo mismo sirve como referencia para la entrada desglosada en la lista final de bibliografías del trabajo, y preserva el anonimato de las informantes. 14. Maquila o maquiladora es un término coloquial que refiere a un modelo de producción industrial, implementado en la frontera norte de México a partir de 
quince años, iniciaron una relación con algún joven que culminó en un embarazo -por lo general, no deseado-, lo cual incrementó la condición de vulnerabilidad que si bien ya era considerable en el entorno inmediato de las jóvenes, aumentó en la forma de presión por el acceso rápido a recursos económicos para solventar los gastos de la maternidad. Además, si bien es cierto que los mecanismos de promoción de la salud y la seguridad por parte de las instancias del Estado han penetrado en varios de los espacios donde se ubican estas jóvenes, sobre todo mediante cursos de capacitación sobre enfermedades de transmisión sexual y métodos anticonceptivos, esta presencia no ha disminuido la tendencia del embarazo de las mujeres a edades tempranas ni el contagio de enfermedades.

Otro aspecto que enfrentan las jóvenes entrevistadas es la imposibilidad de insertarse en los escenarios de reconocimiento institucional en forma, como la escuela y el trabajo formal. Si bien en las entrevistas la mayoría mencionó haber cursado al menos la educación primaria, la deserción escolar se ha presentado entre ellas a una edad temprana por diversos motivos: presión de participar con el ingreso familiar, embarazo, vínculos con algún joven o familiar que motivó la inserción en el mundo del trabajo sexual, así como el inicio del consumo de alcohol y otras drogas:

Dejé la escuela por las drogas: me drogaba primero poco, pero comenzó a gustarme y conocí a varios compas que me la invitaban. No me interesó la escuela, la verdad, es que no sé para qué pueda servir, aquí consigo lo que quiero, tengo para darle a mis dos hijas y no les falta nada ni tampoco a mi mamá [...]. Mis hijas no saben a qué me dedico, y es mejor así. Mi mamá las lleva a la escuela y las recoge mientras yo me vengo aquí [hotel] y pos [sic] nomás estoy [aquí mientras] ellas van

la década de los sesenta por medio del Programa Nacional Fronterizo. En general, se caracteriza por una industria de ensamblaje en donde los materiales que son transformados generalmente no pagan aranceles. 
a la escuela; estoy el resto del día con ellas. En otro trabajo no podría, y aquí sí. (Joven 5,2016 )

Como se anticipaba, los espacios laborales formales para estas mujeres son limitados. Al no tener los grados de estudios requeridos, algunas han intentado trabajar en puestos de limpieza en alguna maquiladora, otras en el trabajo doméstico, e incluso una de ellas manifestó que pudo emplearse por un breve tiempo como recepcionista en un consultorio médico de la zona centro, pero diversos motivos -el ingreso salarial y experiencias de rechazo y violencia que enfrentó- no favorecieron la continuidad en dicho empleo.

Si bien varias de las jóvenes han experimentado en algún momento situaciones de amenaza a su integridad física y personal, en los relatos se observa que dedicarse al trabajo sexual les permite pensar a futuro en un proyecto de vida que gira en función de sus hijos y que no se relaciona directamente con el mundo que enfrenta cada una de ellas.

\subsection{Tensión frente al narcomundo}

La distribución y el consumo de drogas están presentes en la vida de estas jóvenes. En las entrevistas, aparecen constantemente la marihuana, la heroína y el agua celeste $e^{15}$ como parte de un corpus discursivo de figuras inscritas en su lenguaje cotidiano. La referencia del familiar o persona cercana, varón por lo regular, con quien la joven se ha vinculado sentimentalmente, se convierte también en la vía de acceso al consumo de estas sustancias. En ese aspecto, cobra relevancia la figura del proxeneta, aquel individuo que a partir de una relación de dominación sobre la joven se favorece de su inducción forzada por las ganancias generadas por el mercado sexual:

I5. Solvente utilizado en la industria de la piel y el calzado, que por su bajo costo es accesible como inhalante para la población económicamente más desfavorecida. 
Me junté con un chavo y salí embarazada. Él se drogaba y comencé a drogarme, a consumir la pura droga, de todo tipo, llegué a inyectarme, a inhalar piedra [crack], mota [marihuana], todo, descuidé a mi familia, a mi mamá.Yo quisiera ya rehabilitarme, terminar y no seguir más con la droga, pero sabes que cuando te llevan a un centro de rehabilitación te quieres morir, es un ansia bien cabrona la que tienes, te desesperas toda, te quieres ahorcar con lo que sea. Cuando ya te alivianas, sólo te sacan y ¿qué haces?, pos [sic] aunque quieras cambiar tu vida no puedes, te espera el morro con el que estás y te pide que lo alivianes con la droga, y pos [sic] no te queda de otra, a prostituirte, a seguir aquí con los clientes, porque ¿qué más te queda?, otra vida no existe para una. (Joven 4,2016)

El narcomenudeo es un mundo (narcomundo) que se desarrolla a la par de la vida de estas jóvenes. La zona centro de la ciudad, incluso por su ubicación geográfica cercana al cruce internacional con la ciudad de El Paso (Texas), ha sido un escenario históricamente cooptado por los cárteles que se han visto favorecidos por la escasa presencia o complicidad de las instancias del Estado. En los bares, cantinas, hoteles improvisados en edificios de vivienda abandonados, es posible para las jóvenes acceder a la compra de marihuana o alguna otra droga sintética de bajo costo.

El consumo de estas sustancias es para ellas parte de su búsqueda por desvincularse, aunque sea por el breve momento que dura el efecto de la droga, del estado de vulnerabilidad generado por las condicionantes reales que enfrentan. Ingerirla también tiene la intención de transitar por un breve tiempo de olvido durante el acto sexual con el extraño. Sentirse ultrajada, sucia, utilizada, se aminora con la dosis suficiente de droga que permite a la joven un viaje que la separa de su cuerpo físico violentado. Cuando el efecto de la droga pasa, el regreso a una realidad no deseada cierra el círculo del consumo, que vuelve a iniciar cuando se busca no estar presente y se consume de nuevo la sustancia ante la experiencia de vulnerabilidad concreta. 
Ahora bien, ¿qué sentido adquiere para las jóvenes el cuerpo no sólo como recurso de mercado sexual, sino como deseo de la propia feminidad? En las visitas que se realizaron a los lugares de observación, llamó la atención que las jóvenes trabajadoras sexuales dedicaban su tiempo, mientras no estaban con algún cliente negociando o realizando el trabajo sexual, a maquillar su cuerpo para volverlo más atractivo. No obstante, las entrevistas constatan que las jóvenes experimentan un sentimiento de desvalorización de la propia imagen cuando se hacen conscientes de las marcas que las inyecciones de drogas han dejado en sus propias extremidades (brazos, piernas y cuello):

Ya tengo todo el cuerpo bien jodido, mira, no tengo ya vena casi donde pueda picarme, está todo picado, las bolas estas [señala su brazo] pos [sic] son por picarme [...]. No me gusta mi cuerpo, me agüita [entristece] porque pos [sic] así [con las cicatrices] no eres atractiva para los clientes, sólo [para] el que llega bien borracho o drogado porque no le importa porque no se da cuenta [...], pero otros sí te ven mal, les das asco y se van, $y$ eso me pone triste. (Joven 2, 2016)

De esta manera, el cuerpo como autoafirmación va desapareciendo para dar lugar al cuerpo como desecho, residuo que cumple con dar placer a un ser ajeno. Un ejemplo de esto: en una ocasión, durante las entrevistas, se constató la ausencia de una de las jóvenes informantes. Al ser cuestionadas, sus compañeras señalaron que había sido levantada por una patrulla y luego encontrada golpeada en un terreno baldío, con sus senos cortados aparentemente con una navaja. Estas experiencias forman parte de un escenario cotidiano en el que marcar violentamente los cuerpos, como señala Segato (2006), es una práctica que "se dirige al aniquilamiento de la voluntad de la víctima, cuya reducción es justamente significada por la pérdida del control sobre el comportamiento 
de su cuerpo y el agenciamiento del mismo por la voluntad del agresor" (p. 20).

\subsection{Objetos de deseo}

La violencia ha tenido una presencia central en la vida de las jóvenes en la zona centro de Ciudad Juárez. Considerado popularmente como lugar de desapariciones, el centro de la ciudad se coloca en los hechos como el sitio de la urbe en que familiares de mujeres han presentado el mayor número de denuncias al respecto (información obtenida durante observación en campo). Algunas de las desaparecidas han sido luego encontradas sin vida, violentadas, desechadas, en alguna zona desértica a las afueras de la ciudad.

A pesar de esto, estar insertas en el trabajo sexual significa para las mujeres, como ya se dijo, acceder a un pago cuyo monto en otros contextos, sobre todo el laboral formal, exigiría una jornada cinco veces mayor: en promedio, una operaria de maquiladora o trabajadora doméstica obtiene de setecientos a ochocientos pesos por jornada semanal, mientras que las trabajadoras sexuales jóvenes, sobre todo aquellas que han adquirido la habilidad de hacerse de clientes, ganan entre doscientos y cuatrocientos pesos por un trabajo de entre veinte y treinta minutos:

Mira, sabes que a mí este trabajo, te lo juro por dios, que no me gusta. Me da a veces tanto asco sentir así clientes gordos encima de mí. He tratado de dejarlo, por dios que he tratado de dejarlo, y ya nomás necesito dinero, ¿cómo te lo explico?, dejo de venir un mes, dos meses, y me veo nomas bien horcada [sic], y se me hace fácil volver, o sea, que digo: "ay, es que ya no sirve la lavadora, ya no sirve el refrigerador", ya se me hace fácil, sé que aquí vengo y lo consigo fácil, claro que pues [es] a costa de mi sufrimiento, pero lo consigo fácil. (Joven 3, 20l6)

A los clientes no les tenemos miedo, llegan borrachos, drogados, orinados [...]. Te dicen: “ipos [sic] qué, mamacita? Vamos y hazme esto y

\section{6}


aquello".Pos [sic] primero que muestren la feria, si tienen con qué pagar, [y si sí] entonces ya te pones de acuerdo [sobre] qué pueden hacer, porque no por unos doscientos pesos dejo que lo hagan sin condón, te tienes que cuidar, pero si llegan con más dinero, con un melón [mil pesos] o más, pos ya ve una si se arriesga. (Joven 2, 2016)

Como refieren dos de las jóvenes entrevistadas, la experiencia en el trabajo sexual les ha permitido generar una serie de estrategias individuales y colectivas para defenderse frente a los clientes que, como ellas mismas mencionan, "se quieren pasar de listos". Sin embargo, en quien las jóvenes encuentran una mayor posición de vulnerabilidad es con la policía, quien se supondría haría que ellas experimentaran mayor seguridad y resguardo del entorno inmediato en el que se mueven: la policía está integrada a una estrategia de criminalización del control sexual de las mujeres.

Frente a las categorías de lo femenino privilegiadas por la institucionalidad tradicional propia de la familia, la escuela o el trabajo formal, en que las figuras femeninas valoradas giran en torno a lo doméstico y la visión de la mujer como dependiente, decente, fiel, virtuosa, casta, burguesa, madre, protectora, etc., surgen en ese mismo imaginario axiológico figuras opuestas contra las que se debe luchar hasta su eliminación. En las categorías indeseables, se encuentran la mujer hipersexual, la salvaje, la independiente, indecente, promiscua, inmadura, impura, obrera, descarada, etc. En palabras de Elvira Villa Camarma (2010), "la figura de prostituta, de mala mujer, aparece en oposición necesaria a la figura de mujer virtuosa, la esposa fiel y abnegada" (p. 163). La puta se convierte en una figura estigmatizada de la joven trabajadora sexual que adquiere presencia en las redadas, levantones y detenciones arbitrarias constantemente llevadas a cabo por operativos policiales cuya única finalidad es someter los cuerpos de estas jóvenes, además de hacerlas entregar las ganancias obtenidas en el día del trabajo. 
Aquí, el Estado y sus dispositivos de ordenamiento, en vínculo con actores sociales que han defendido esta moralidad excluyente, actúan como salvaguardas del deseado orden moral cuya legitimación se centra en el castigo a la mercantilización del cuerpo femenino con fines sexuales. Resultado de ello, la mujer joven, pobre, que no puede acceder a otras opciones económicas más que la de ofertar sus servicios, ve incrementada su indefensión social y vulnerabilidad.

No se trata de reducir a la mujer joven a un determinismo moralista que coloque al trabajo sexual como algo negativo que debe ser eliminado del escenario de vida de estas jóvenes y los habitantes de la zona de la ciudad bajo estudio. De entrada, la libre decisión en torno a la gestión y uso del propio cuerpo por parte de cualquier persona, así como el derecho a obtener ingresos por la comercialización libre de la sexualidad constituyen estrategias clave en la búsqueda de superar la condición de vulnerabilidad que enfrentan cotidianamente estas jóvenes. El problema más bien consiste en que las condiciones de exclusión y vulnerabilidad que enfrentan estas jóvenes las colocan en una clara situación de indefensión frente a la presencia moralizante patriarcal.

Un imaginario que ha permeado diversos espacios en los que se desplazan las jóvenes en Ciudad Juárez se sostiene por la creencia cada vez mayor de que en dicha ciudad es permitido violentar, matar, eliminar a una persona sin que nadie lo impida o se enfrente un castigo por ello. Las mujeres jóvenes generan entonces sus experiencias de vida en un imaginario que las coloca como objeto codiciado de una masculinidad opresora para la cual ser mujer, joven, pobre y trabajadora sexual las convierte en condición de desecho: "Para la mayoría, una es una puta que vende su cuerpo, pero no saben lo que está detrás de una, que también soy madre, tengo una hija, y a ella nunca le falta leche y vestido" (Joven 4, 2016). 
Esta estrategia de rechazo de las mujeres jóvenes permea diversos sectores de la población y se coloca en la justificación de la institucionalidad prevaleciente. En este sentido, dan claridad al respecto las declaraciones de un exfuncionario de alto nivel de la Presidencia Municipal en relación al fenómeno del feminicidio en esta frontera: "es una leyenda negra que aprovecharon empresarios y promotores extranjeros para echarle tierra [obstaculizar] a este municipio, con el propósito de evitar que las empresas vinieran a una ciudad que competía favorablemente en la instalación de empresas mundiales" (Pérez Silva, 2015).

La violencia que enfrentan las mujeres jóvenes trabajadoras sexuales en el centro de la ciudad, no sólo física sino también afectiva y simbólica, ha sido una constante que ha caracterizado la institucionalidad heteronormativa desde sus diversas trincheras. El vínculo entre el paisaje de abandono de la zona, el trabajo sexual y el mercado informal ha sido, por ejemplo, uno de los argumentos para promover la intervención urbana por parte de organismos públicos vinculados al Estado mexicano y actores empresariales.

Proyectos para la revitalización de la zona centro de Ciudad Juárez, como el Plan maestro de desarrollo urbano del centro histórico de Ciudad Juárez, elaborado en el 2014 por el Instituto Municipal de Investigación y Planeación de esta ciudad, han exigido la realización de una serie de proyectos de demolición y rehabilitación urbana para "consolidar la zona como la principal puerta de entrada a la ciudad y al país" (Instituto Municipal de Investigación y Planeación, 2014 , p. 14). Este tipo de planes oficiales coloca como problemas prioritarios de atención detectados en la zona centro de Juárez la imagen urbana deteriorada, la prostitución, la existencia de olores fétidos, el mercado informal y el alto número de indigentes que transitan por la calle (Instituto Municipal de Investigación y Planeación, 2014). 
Las etiquetas de abandono, descomposición, fétido, indigencia o mendicidad se apoderan a su vez de un imaginario de clase en el cual ser pobre, mujer, joven y trabajadora sexual constituye por ende marcas desvalorizadas ante la mirada de quienes se dicen portavoces de las buenas costumbres y la moralidad deseada. En la presentación pública del plan maestro antes señalado, el uso de recursos visuales para mostrar imágenes a futuro de la propuesta de remodelación, reconstrucción y readaptación de calles, edificios y plazas de la zona de intervención, para lo cual el Gobierno utilizó figuras masculinas y femeninas estilizadas, blancas, aburguesadas, contrasta con el paisaje real de los edificios abandonados entre los que transitan mujeres jóvenes trabajadoras sexuales cuya indumentaria muestra parte de su cuerpo con la intención de atraer la mirada de algún cliente que aminore, mediante el pago de sus servicios, su cotidiana situación de precariedad. Finalmente, como señala Butler (2010), "ser un cuerpo es estar expuesto a un modelado y a una forma de carácter social, y eso hace que la ontología del cuerpo sea una ontología social” (p. 15).

\subsection{Cuerpos negociados, vida precaria}

Butler refiere como vidas precarias a aquellas que enfrentan una "condición políticamente inducida en la que ciertas poblaciones adolecen de falta de redes de apoyo sociales y económicas, y están diferencialmente más expuestas a los daños, la violencia y la muerte" (Butler, 2010, p. 16).

En los últimos años en Ciudad Juárez, así como en el resto del país, se ha presentado un escenario caracterizado por un orden colapsado (Reguillo, 2012) que resulta de diversas violencias que han marcado los cuerpos de jóvenes hombres y mujeres. Esta misma gramática visibiliza el horror como categoría central para comprender la experiencia de vida de las jóvenes trabajadoras sexuales. El cuerpo de la joven constituye una de las evidencias más contundentes de la 
violencia que enfrenta su grupo al estar compuesto por mujeres desplazadas de los marcos de regulación y reconocimiento socialmente instituidos, que definen criterios de aceptabilidad y valoración.

Estos marcos, en tanto operaciones de poder (Butler, 2010), delimitan la esfera de lo permitido y generan algo exterior a lo legible y materializable como un cuerpo reconocido. Esos mismos marcos definen qué vidas vale la pena proyectar como ideales en una escala axiológica, y qué otras son reducibles a objetos de satisfacción o consumación del deseo ajeno. Al respecto, el marco normativo heteropatriarcal constituye el mapa inteligible por el cual ciertas masculinidades asumen el protagonismo de una violencia exacerbada frente al cuerpo femenino, y en particular frente al cuerpo de la trabajadora sexual.

Rita Segato (2006) expone cómo se ha gestado progresivamente una violencia expresiva ${ }^{16}$ en el contexto reciente de la frontera norte mexicana. En un análisis centrado en el caso de cuerpos de jóvenes asesinadas en la región, la autora describe con gran acierto un escenario que

muestra la relación directa que existe entre capital y muerte, entre acumulación y concentración desreguladas y el sacrificio de mujeres pobres, morenas, mestizas, devoradas por la hendija donde se articula[n] la economía monetaria y economía simbólica, control de recursos y poder de muerte. (Segato, 2006, p. II)

\section{Conclusiones}

Las narrativas que las jóvenes generaron a lo largo de las entrevistas realizadas permiten observar la voracidad

16. La autora separa la violencia expresiva de la instrumental, necesaria en la búsqueda de cierto fin. Para ella, la violencia expresiva "engloba y concierne a unas relaciones determinadas y comprensibles entre los cuerpos, entre las personas y entre los territorios" (Segato, 2006, p. 9). 
insaciable de un contexto sociohistórico dominado por la complicidad de una producción industrial caracterizada a su vez por la reducción de los cuerpos hasta sus mínimas condiciones de supervivencia. El cuerpo negociado en el trabajo sexual de las mujeres, sexualmente atrayente a un varón para quien significa más un momento de desecho, constituye la manifestación cotidiana del miedo y el horror en la experiencia de estas jóvenes.

Como se pudo observar, la experiencia de vida precaria de las jóvenes trabajadoras sexuales está anclada a la obtención de un pago ocasional según una jornada acordada y a redes de complicidad condicionadas por el espacio íntimo y que trabajan en función de la satisfacción de necesidades generalmente exigidas por la pareja masculina, todo ello en un tejido cotidiano que configura una ontología excluyente en torno a la producción de sujetos.

Como bien señala Butler, "una vida tiene que ser inteligible como vida, tiene que conformarse a ciertas concepciones de lo que es la vida, para poder resultar reconocible" (2010, p. 21). Ser joven, pobre, trabajadora sexual, es cargar, como se observó en el artículo, una marca existente en el imaginario de perversión y deleite de un sujeto masculino que ostenta el pago como expresión de poder y sometimiento del cuerpo de la joven, o en otras palabras, el consentimiento o acuerdo por el pago del servicio enmascara las relaciones de explotación que sufren las mujeres frente al poder de quien considera tener derecho a la explotación de su cuerpo (Gimeno, 2011; De Miguel, 2015). En este sentido, los autores del presente artículo no comparten aquellas visiones que reducen la aceptabilidad del mercado sexual a una cuestión de consentimiento mutuo entre dos personas, ya que una visión como esa oculta la creciente precarización de vida que enfrentan las jóvenes trabajadoras sexuales en el contexto neoliberal que caracteriza a una ciudad fronteriza como Juárez. 
Este último aspecto cobra relevancia en un momento en que el debate frente al marco normativo del trabajo sexual en México cuestiona la reducción del fenómeno a un problema jurídico, sin tomar en cuenta otros aspectos clave de análisis ligados a las condiciones de explotación y vulnerabilidad que la ideología de la libre elección y la igualdad, propia del neoliberalismo, se ha encargado de ocultar:

Uno de los equívocos más persistentes en este debate es la posibilidad de que quien defiende el uso o la regulación de la prostitución sea automáticamente y sólo por esa defensa considerada feminista radical y prosexo. Esto tiene que ver con que desde esta perspectiva se suele insistir en que, al regular la prostitución, además de los derechos de las mujeres que lo ejercen, también se protege la libertad sexual[,] cuando en realidad lo que se protege es una determinada masculinidad y una determinada sexualidad masculina cuya hegemonía y no cuestionamiento dificulta o impide la igualdad entre los sexos. Desde su posición prosexo, las feministas que no cuestionan o que defienden estas masculinidades pasan por revolucionarias y radicales sexuales, cuando en realidad no hay nada más conservador que apoyar una institución tan milenaria cuya función es apuntalar la desigualdad, mientras que lo radical sería pretender cambiar los roles sexuales, de género, combatir el binarismo sexual y las prácticas hegemónicas que se naturalizan a través de, por ejemplo, el uso de la prostitución. (Gimeno, 20I I, p. 225)

El debate feminista en el cual se coloca Gimeno (2011) en la cita anterior apuntala la necesidad urgente de la generación de un proyecto de moral feminista que irrumpa en el peso dominador de la moral heteropatriarcal y que no se reduzca a la alternativa del trabajo sexual como opción legal de transacción sexual basada en la libre elección. El problema es de fondo: se requiere desenmascarar un modelo tardocapitalista que cosifica a los cuerpos femeninos y masculinos, asociándolos a mercancías que participan en la voracidad de un mercado de producción de más cuerpos desechables. 
Una trayectoria político-moral de reconocimiento que diluya las relaciones de explotación y exclusión cobra relevancia en el contexto actual de Ciudad Juárez, dominado, como se dijo, por un moralismo de negación que reduce la libre elección de las mujeres sobre sus cuerpos a la satisfacción de un mercado de placer que nutre una construcción de masculinidad hegemónica. Como se observó en los relatos de las entrevistadas, el peso que adquiere el imaginario del cuerpo como mercancía y su relación con dinámicas de sujeción exigen un debate que pueda plantear alternativas a la creciente precarización de la vida de las jóvenes en el contexto actual de pobreza, exclusión social y marginalidad.

Por otro lado, Ciudad Juárez se ha constituido como ejemplo, en los últimos años, de un paisaje de crisis resultado de implementar una visión de política neoliberal basada en la generación de una industria maquiladora de exportación, la penetración del narcomundo en las trayectorias de vida de cientos de jóvenes que ven cada vez más negadas sus opciones de producción de alternativas sólidas de futuro, y la creciente violencia con expresión más cruda de barbarie contra los cuerpos femeninos. Ante esto, como se señaló al inicio, el debate con respecto a la práctica sexual y la libre elección en la gestión de los cuerpos es un aspecto clave en la reflexión hacia un marco normativo que otorgue certidumbre a la vida de las jóvenes trabajadoras sexuales.

Evidentemente, el problema es de mayor profundidad y no exclusivamente normativo o axiológico. La creciente pobreza y exclusión que enfrentan las jóvenes en Ciudad Juárez (Salazar Gutiérrez, 2016) y en general un porcentaje importante de la población en otras regiones del país, así como la penetración de un imaginario androcentrista anclado en la representación del cuerpo femenino como un objeto de dominación obligan a construir un nuevo pacto social que se sostenga en una política del reconocimiento y en la generación de alternativas -políticas, laborales, fami- 
liares, sexuales-reales y sólidas que otorguen certidumbre a las trayectorias de vida de las jóvenes.

Butler, J. (20I0). Cuerpos que importan. Sobre los límites mateBibliografía riales y discursivos del sexo. Buenos Aires: Paidós.

Connel, R. W. (2003). Masculinidades. México: Programa Universitario de Estudios de Género, UNAM.

De Miguel,A. (20I5). Neoliberalismo sexual. El mito de la libre elección. Madrid: Cátedra.

García Pereyra, R. (20I3). Diversiones decentes en una época indecente. México: Universidad Autónoma de Ciudad Juárez.

Gimeno, B. (20I I). La prostitución. Barcelona: Bella Terra.

Gira Grant, M. (2016). Haciendo de puta. La labor del trabajo sexual. Santiago: Editorial Pólvora.

Instituto Municipal de Investigación y Planeación (20 I4). Plan maestro de desarrollo urbano del centro histórico de Ciudad Juárez. Recuperado de http://www.imip.org.mx/centro/ Joven I (2016). Entrevista personal realizada a joven trabajadora sexual [S. Salazar, entrevistador]. Ciudad Juárez, México.

Joven 2 (20I6). Entrevista personal realizada a joven trabajadora sexual [S. Salazar, entrevistador]. Ciudad Juárez, México.

Joven 3 (2016). Entrevista personal realizada a joven trabajadora sexual [S. Salazar, entrevistador]. Ciudad Juárez, México.

Joven 4 (20I6). Entrevista personal realizada a joven trabajadora sexual [M. Curiel, entrevistadora]. Ciudad Juárez, México.

Joven 5 (20I6). Entrevista personal realizada a joven trabajadora sexual [M. Curiel, entrevistadora]. Ciudad Juárez, México.

Juliano, D. (2002). La prostitución: el espejo oscuro. Barcelona: Icaria. 
Bibliografía
Lamas, M. (20I4). Cuerpo, sexo y política. México: Océano. Morcillo, S., y Varela, C. (20I6). Trabajo sexual y feminismo. Una filiación borrada. La ventana. Revista de estudios de género, $v(44), 7-23$.

Osborne, R. (1989). Las mujeres en la encrucijada de la sexualidad. Una aproximación desde el feminismo. Barcelona: Ediciones La Sal.

Pérez Silva, C. (19 de febrero de 20I5). "Leyenda negra”, los feminicidios en Ciudad Juárez, dice el alcalde. La Jornada. Recuperado de http://jornadabc.mx/frontera-norte/ I 9-02-20 I5/leyenda-negra-los-feminicidios-en-ciudad-juarez-dice-el-alcalde

Petherson, G. (2002). El prisma de la prostitución. Madrid: Talasa.

Reguillo, R. (2010). Retóricas de la seguridad. La invisibilidad resguardada: violencia(s) y gestión de la paralegalidad en la era del colapso. Diálogos transdisciplinarios en la sociedad de la información, (2), 33-44.

Reguillo, R. (2012). De las violencias: caligrafías y gramática del horror. Desacatos, (40), 33-46. doi http://doi. org/ $10.29340 / 40.254$

Salazar Gutiérrez, S. (2016). Jóvenes, violencias y contexto fronterizo. La construcción simbólica de la relación vida-muerte en colectivos juveniles. México: Colofón.

Segato, R. L. (2006). La escritura en el cuerpo de las mujeres asesinadas en Ciudad Juárez. Territorio, soberanía y crímenes de segundo estado. México: Universidad del Claustro de Sor Juana.

Speckman Guerra, E., y Bailón Vásquez, F. (coords.) (2016). Vicio, prostitución y delito. Mujeres transgresoras en los siglos xIX $y$ Xx. México: UNAM.

Taylor, S. J., y Bogdan, R. (1996). Introducción a los métodos cualitativos de investigación: la búsqueda de significados. México: Paidós. 
El cuerpo negociado, el cuerpo mercancía. Trabajo sexual y precarización de la vida en Ciudad Juárez, México

Valenzuela Arce, J. M. (20I2). Sed de mal: feminicidio, jóvenes | Bibliografía y exclusión social. México: Colef.

Villa Camarma, E. (2010). Estudio antropológico en torno a la prostitución. Cuicuilco, I 7(49), I57-I 79. 